Volume 2, Issue 9, August 2016, Pages 47-53

DOI: $10.18775 /$ ijmsba.1849-5664-5419.2014.29.1005

URL: http://dx.doi.org/10.18775/ijmsba.1849-5664-5419.2014.29.1005

\title{
The Dilemma of the Optimal Condition an Exploration of the Strategic and Social Consequences of the Organizational Change Imperative
}

\author{
${ }^{1}$ Paul D. Nugent, ${ }^{2}$ Richard Montague, ${ }^{3}$ Emilio Collar \\ 1,2,3 Management Information Systems Department, Western Connecticut State University, Westside \\ Classroom Building, Room 203, Danbury, CT 06810, United States
}

\begin{abstract}
This paper explores the implications of change dilemma. The importance of the this topic lies in everyday's need for organizations to change to survive or thrive yet there is no monolithic or simple thory that explains or prescribes organizational change. There are objective and subjective problems of the optimal condition . This paper discusses the political and sociological problems pertaining to the assumption of an objective optimal condition. We frame the real potential for this condition and its positive and negative strategic and social impacts from an Organization Theory (OT) perspective. Further, an aricle discusses positive and negative consequences of the bias towards change.
\end{abstract}

Keywords: Change dilemma, Optimal condition, Objective optimal condition, Organization theory

\section{Introduction}

This paper is a theoretical exploration of an increasingly common dilemma for organizations. Consider that an organizational condition (e.g., strategy, structure, technology, product, culture) is objectively optimal. This means it would be irrational for the organization to change from this optimal state to a suboptimal state. However, we argue, that, today, the internal and external pressures to change are so strong and ubiquitous that organizations are often forced to change away from the optimal condition. This paper does not draw upon systemic empirical data to assess the extent to which organizations reach optimal conditions nor how often they are forced to change in this manner. Rather, we frame, from an Organization Theory (OT) perspective, the real potential for this condition and it's positive and negative strategic and social. The political and sociological problems pertaining to the assumption of an objectively optimal condition are also discussed. Ultimately, the purpose of this paper is to theorize about what could be considered the zeitgeist of change in organizational studies and its positive and negative effects on organization-level open governance as well as the social dynamics within the organization.

\section{Organizational Change}

If there is any single theme that captures the essence of management ideology over the last five decades or so, it is organization's need to change to survive or thrive. Whether it is simply to be innovative to gain market share or to adopt new processes for internal efficiency, the logic and wisdom of change permeates organizational thought. Scholars offer frameworks that explain why change is necessary. For example, in population ecology, Hannan \& Freeman (1989) identify three basic theories of change that each has its unique logic and explanatory power. First, selection theories focus on the changing environment and how the pace of organizational change must keep up with the pace of environmental change. Here, organizational change is seen as more random and is prone to inertia if the organization is large. Second, adaptation theories grant the organization more ability to consciously design new 
internal systems and processes to match environmental demands. These theories include contingency theory, dependency theory, Marxist theory. Contingency theory strives to achieve a match between the change and the environment. Dependency theory implies that organization attempts to influence the environment to reduce uncertainty. Marxist theory strives to achieve higher levels of control over the worker and production processes (Hannan \& Freeman, 1989). Transformation theory stresses that some organizational changes are purely random, as in biological mutations, organization has little prescience or intelligence over what changes will be selected by the environment.

More recently, organizational theorists have identified more fine-grained and overlapping sources of change within organizations (e.g., Graetz \& Smith, 2010). Based on their analysis they state:

Our argument is that understanding change as part of continuing work in progress calls for a much broader canvas that seeks out competing voices and works with the resulting ambiguities, contradictions, and tensions of messy reality. We advocate a multi-philosophy approach because continuity depends on change as much as change depends on continuity. [p. 136]

Their philosophies of change largely overlap the mechanisms in the selection, adaptation, and transformation theories from population ecology, but they stress the importance of considering other change sources. These include institutional sources in which organizations experience pressures to maintain legitimacy in organizational fields and worker psychology which emphasizes Organizational Development (OD), kinds of variables such as emotional experience and motivation. Also, they identify political aspects of conflict and power, cultural factors such as values and resistance to change, system thinking, and postmodern sources of organizational change (Graetz \& Smith, 2010).

From these perspectives, it is clear that there is no monolithic or simple theory that explains or prescribes organizational change. Environments are highly dynamic and impose both market and institutional pressures on organizations. In addition, the internal dynamics of the organization which includes individual experience/needs, conflict over resources and ideologies, and broader cultural belief systems, all contribute to understanding how and why organizations change (Tsoukas, 2002). It is within this context that we will now turn our attention to the theoretical case in which, given all of the change contexts mentioned above, there is an the objective problems of optimal organizational condition.

\section{The Objective Problem of the Optimal Condition}

Herbert Simon introduced the notion that in most cases human beings make decisions under conditions of bounded rationality (Simon, 1956). This means that the information needed to assess all alternatives and their true probabilities characterizing optimal decision-making is not available or is too costly. This leads to strategies in which the decision-maker will settle upon the first alternative that satisfies a certain threshold need. He named this strategy satisficing. Furthermore, ambiguity, uncertainty, and satisficing have been found to be central features of decision-making in organizational life (March \& Simon, 1958; March \& Olsen, 1976; Stinchcombe, 1990).

Assuming that this captures the way in which organizational decisions about whether or not a current state of affairs is optimal or not, it is useful to consider models of statistical inference such as Type I and Type II error. If a shift has actually occurred away from an optimal state, there is still a non-zero probability that available data will fail to indicate the shift resulting in inaction (Type 2 error). However, if no shift has actually occurred, and you are still in 
the optimal state, some data may fit the narrative that you are no longer in the optimal state compelling action toward a suboptimal state (Type 1 error).

In this objective case, no systemic driver tilts the scales toward either one of these errors. That is, this objective case assumes that the decision-maker has no particular bias toward believing that a shift has or has not occurred. However, the main argument in this paper is that organizations are moving in a direction in which they experience internal and external pressures that introduce this bias and dramatically increase Type I error making a shift away from the optimal relatively more likely. In the remainder of this paper, we will assume that an optimal condition exists, that this bias toward change exists, explore possible sources of this bias, and consider both the positive and negative consequences of this bias.

\section{The Subjective Problem of the Optimal Condition}

Most of us have experienced our computer operating systems, email applications, products, services, or processes within our organizations changing in a manner that feels like a step backwards. Why did they do that? One answer could be that they have done their due diligence and performed studies that show, objectively, that the change is a shift from some suboptimal state of affairs to a more optimal state. While these kinds of assessments do take place, more likely than not the driving force behind the change is simply that change, as a norm, is expected by those within or those outside the organization.

\subsection{Legitimacy}

As mentioned previously, organizations are embedded in organizational fields in which customers or other organizations expect them to demonstrate what are considered to be legitimate processes or structures. This means that there are cultural norms that develop within these organizational fields about what is expected and failure to meet these expectations signals to stakeholders that the organization may be weak or simply not keeping up with industry/sector trends (DiMaggio \& Powell, 1991).

Pressures for legitimacy will drive the organizations to change in order to be in line with these expectations. This will be, in most cases, a rational move from a perceived sub-optimal state to an optimal state. Yet, in more recent modernity, some institutional pressures involve the very expectation that the organization must be perceived as in a perpetual state of change. That is, even if an objective optimal state has been achieved relative to all other institutional pressures, there remains residual institutional pressures to change because change itself, independent of form, is expected. One could speculate that this particular institutional pressure evolved from the differentiation marketing strategy identified and promoted by strategy scholars such as Michael Porter (2008). In the differentiation strategy organizations attempt to gain market share by putting forth products or services that are different (not necessarily objectively better) than their competitors'.

In summary, to the extent that these institutional pressures compel organizational actions that succeed in expanding market share through differentiation strategies, these are rational actions that move from the suboptimal state toward the optimal state. However, we argue, this will also often lead, when it is a change for change's sake, to an organization's products or services shifting from an optimal state to a suboptimal state leading to loss of market share. While this is a theoretical claim, one need only draw upon one's own experience as a consumer to identify empirical examples where this problem has likely occurred. This also lays a theoretical framework within which to perform future empirical studies in which customers or other environmental stakeholders are queried as to whether a focal organization's change was perceived as a shift away or toward a more optimal state. 


\subsection{Framing Non-Change as Failure}

Internal to organizations processes and many job roles define success as the ability to enact change. Change is the requirement and the expectation. Therefore, if the existing condition is objectively optimal, these processes and roles will fail their charter, and this is another theoretical reason for shifts from the optimal to the sub-optimal.

Organizational Development (OD) programs and quality control paradigms have been implemented by organizations for many decades now, and there is a clear common thread that change is vital and that the status quo is to be feared or framed as a frictional drag or inertia (Piderit, 2000). Organizational processes such as Six Sigma, Statistical Process Control (SPC), Capability Maturity Model Integration (CMMI) and Reengineering all share a fundamental philosophy of continuous improvement and the assumption that the optimal state is never achieved.

Reengineering and Six Sigma, in particular, offer procedures for managers and workers to formally identify "as-is" process flows in a manner that will help to find areas for process improvements - the "should be" or "could be" cases. Therefore, these process paradigms approach the existing organizational case as already sub-optimal and, like a sick patient, in need of diagnosis and treatment (Recker, 2005). What happens, when a team specifically dedicated to diagnosing a particular process, finds no obvious way to improve the process? While some teams may be bold enough to report upward that the process is perfect as far as they can tell, it is more likely that they would equate this outcome to a failure, and this would motivate them to recommend ways to change the process simply to meet the expectations of their superiors.

More profoundly, this line of reasoning can easily be extended from ad-hoc teams to many formal roles within the organization. Some worker and managerial roles have written into their job descriptions the expectation that they will identify organizational processes that are in need of improvement and enact change. This means that in many cases individuals in these roles will need to evaluate processes that are more familiar to others (those workers who have developed and/or are executing the process) than they are to them. Therefore, they will often lack the detailed and context-based knowledge about the process, and yet, to be seen as performing their job well by superiors will nonetheless need to find areas for improvement. To the extent that these roles lead to real change, it is reasonable to assume that because they are based on an inferior level of process knowledge, that they will, in many cases, shift away from the optimal condition.

\section{Positive Consequences of the Bias Toward Change}

Change, even if it is a move away from the optimal condition, may still be beneficial to the organization in the long run. As we have seen, organizations must establish and maintain legitimacy within organizational fields (DiMaggio \& Powell, 1989, 1991). Even if this means that an environmental stakeholder perceives a product or service as shifting from optimal to suboptimal, the focal organization, at a minimum, retains its legitimacy simply because it upholds the façade of change. This "changing for change's sake" behavior upholds the environment's overall expectation that the organization is not stagnating and is actively adapting even if, at times, it may be a mistake. Furthermore, others have argued that even if the purpose of the change is not altogether clear, there is a reinvigorating benefit in breaking up routines, breaking down silos, and generally "shaking things up" (Phanish \& Gulati, 2010).

Also, with change, whether for better or worse, comes organizational learning. Karl Weick's (1977) concept of enactment is a general theoretical framework in which acting itself makes things visible to the organization that otherwise would have been hidden. Organizations learn new things about their internal processes and external relationships when actions are taken and responses are observed. Many organizations embrace this philosophy at the managerial level and tell their workers to go forth and enact change even if it leads to failure because of the 
opportunity for learning that will take place. It is reasonable to assume that for many organizations and for many potential changes, this is a rational strategy.

\section{Negative Consequences of the Bias Toward Change}

Although empirical data would be helpful, there is no doubt that there are times in which the pressure for legitimacy compels organizations to modify their products or services in a manner that displeases and loses customers (e.g., Mochizuki, 2015). Chat rooms and blogs often reflect customer confusion and hostility when services such as computer operating systems or Email formats change. While on the one hand some of this can be attributed to a general discomfort with learning new systems/schemes that are objectively superior, on the other hand it often reflects a more deep-seated belief that the product or service truly did take an undesirable step backward. Organizations often "beta test" these kinds of changes to avoid these types of failures, however, it is clear that these failures can and do occur.

According to population ecology, large-scale reorganization introduces vulnerabilities similar to newness where failure is associated with the rebuilding of trusting relationships and the redefining of roles and tasks. For example, Hannan and Freeman (1989) state:

The processes of dismantling one structure and building another make organizational action unstable. Consequently, the variance of quality and timeliness of collective action decline during reorganization. That is, the process of reorganization lowers reliability of performance. [p. 83]

Therefore, while we saw enactment to be beneficial to the organization from a learning point of view, enactments that involve larger scale changes to organizational processes and roles place the organization in a state of flux that will diminish performance for a period of time. This means, in the context of our analysis, that the change creates a temporary, although potentially fatal, the shift from an optimal state to a sub-optimal state.

Finally, the requirement for organizational processes and roles to frame non-change as a failure can have negative social effects. As mentioned earlier, the process or role occupant that is tasked with evaluating a process is usually not as familiar with the history and details of that process as those who have been involved with it intimately for months, years, or decades. This leads to resentment on the part of those closest to the process. While some quality control paradigms recommend that the "inputs" from the workers be factored into the change decisions, the inevitable disparity in what these paradigms refer to as "profound knowledge" maintains a level of resentment.

From a labor studies tradition, this dynamic has even deeper implications. Beyond mere resentment that one's turf is being encroached upon, there is a general matter of culture, community, and alienation. According to theories of alienation, workers experience actualization and meaningfulness when they are able to produce a good service that is valued and found to be useful by others (e.g., Marx, 1956; Beamish, 1992; Blauner, 1964). Social spaces are "looking glasses" in which human beings see one another and are keenly aware that they are being seen and evaluated (Marx, 1844; Mead, 1934; Cooley, 1994). In this vein, to the extent that a group of workers has worked together to develop, evolve, and maintain a particular production process and become actualized through these activities, the arrival of groups or individuals that are less familiar with these processes and who assume that it must require change, is a failure to offer them their due respect. This dynamic extends to "the old guard" that has built an organization from its foundation only to encounter a new crop of workers who are given the charge by management to find nothing sacred about what has been done in the past and to succeed primarily by forcing change. We see, then, a double negative in which not only are processes changed somewhat arbitrarily to a less optimal state, but 
those who are core members of the organization who have, in essence, "owned" these processes become alienated from their work and from their involvement in what was previously experienced as a community.

\section{Revisiting Assumptions}

The analysis, so far, has been based on the critical assumption that objective optimal conditions exist. This assumption is problematic and seen as dangerous to modern philosophers, Marxists, and postmodernists who deny universals, see reality as a social construction, and view change as the outcome of conflict (Wittgenstein, 1958; Berger \& Luckmann, 1966; Perrow, 1986; Clegg, 1990; Giddens, 1991; Goulimari, 2007). From this perspective, any structural, process, product, or cultural change represents a shift in power from one group to another. That is, they would assume instead that if an objective or universally valid optimal condition is possible, it would mean that an equitable or ethical balance of power between groups in conflict has been achieved. This paper has taken the point of view of organizational leadership and what is rational for the success and survival of the whole organization as a purposeful goal-oriented collective, but this is only one of many valid perspectives on change and its social implications.

This introduces new points of inquiry in which researchers can frame the power inherent in organizational management-backed change programs (i.e., Six Sigma, Reengineering, SPC, etc.) or inherent in various formal roles within the bureaucratic structure and the role these powers play in conflict situations (Kunda, 1992; Nugent \& Collar, 2014). As we have already seen, there are times when a group that is more intimate with process details is forced to change processes because a group or an individual who knows less about the process has the power to force the change. Therefore, questions about conflict and power in the context of change could augment the existing labor studies literature that is has been more concerned with questions of the deskilling and alienating effects of new technologies.

\section{Conclusion}

Through pressures for legitimacy, organizational-level quality programs, and change oriented organizational roles, there is a possibility that an existing process, product, or service might already be optimal and is not in need of change. This situation presents a unique dilemma to organizations. This paper explores the implications of this dilemma, and while change, even when it is not necessary, can still be beneficial to an organization, there are negative consequences that should compel managers to think more deeply about how to govern change within their organizations or their organizational field. Also, theories about reality and objectivity inspired by the linguistic turn in philosophy remind us that framing "optimal conditions" from the point of view of management marginalizes other valid points of view and that politics, power, conflict and ambiguity must be factored into the context of our analysis.

As a theoretical paper, we hope that these conclusions will encourage other researchers to establish a more empirically based understanding of the causes and consequences of shifts from optimal to suboptimal conditions and also an understanding of how evaluations of optimality may differ from group to group within the organization. Ultimately, however, we hope this theoretical exploration serves as a caution, in the age of what is truly the zeitgeist of change, which at times change is not rational and that to change for change's sake can have negative consequences.

\section{References}

- Beamish, R. (1992). Marx, Method, and the Division of Labor. University of Illinois Press: Chicago 
- Berger, P. L. \& Luckmann, T. (1966). The Social Construction of Reality. Anchor Books, Doubleday: New York

- Blauner, R. (1964). Alienation and Freedom. Chicago: University of Chicago Press

- Clegg, S. R. (1990). Modern Organizations. Sage Publications: London

- Cooley, C. H. (1994). "Looking-Glass Self." Pp. 266-68 in The Production of Reality edited by Peter Kollock and Jodi O'Brien, Pine Forge Press: Thousand Oaks

- DiMaggio, P. and Powell, W. W. (1983). "The Iron Cage Revisited: Institutional Isomorphism and Collective Rationality in Organizational Fields." American Sociological Review, 48 (April), 147-60, CrossRef

- DiMaggio, P. and Powell, W. W. [Eds.] (1991). The New Institutionalism in Organizational Analysis. The University of Chicago Press

- Giddens, Anthony (1991). Modernity and Self Identity. Cambridge: Polity Press

- Goulimari, Pelagia [ed.] 2007 Postmodernism. What Moment? Manchester: Manchester University Press

- Graetz, F. \& Smith, A. (2010). "Managing Organizational Change: A Philosophies of Change Approach", Journal of Change Management Vol. 10, No. 2, 135-154, June, CrossRef

- Hannan, M. T. \& Freeman, J. (1989). Organizational Ecology. Harvard University Press

- Kunda, G. 1992. Engineering Culture. Temple University Press: Philadelphia

- March, J. \& Olsen, J. (1976). Ambiguity and Choice in Organizations. pp. 10-23. Copyright Universitesforlaget, Oslo, Norway

- $\quad$ March, J. \& Simon, H. (1958). Organizations. John Wiley \& Sons, Inc.

- Marx, K. (1844). "Comment on James Mill," Economic and Philosophical Manuscripts of 1844

- Marx, K. (1956). Karl Marx, Selected Writings in Sociology \& Social Philosophy. Translated by T. B. Bottomore. McGraw-Hill: New York

- Mead, G. H. (1934). Mind, Self and Society. University of Chicago Press: Chicago

- Mochizuki, T. (2015). "Sony CEO Remains Committed to Consumer Electronics," Wall Street Journal. January 7, 2015.

- Nugent, P. D. \& Collar, E. (2014). "The Hidden Perils of Addressing Complexity with Formal Process: A Philosophical and Empirical Analysis." Proceedings of the Complex Systems Design \& Management (CSD\&M) Conference. Paris, France

- Perrow, C. (1986). Complex Organizations: A Critical Essay. Third Edition. McGraw-Hill, Inc.: New York

- Phanish, F. V. \& Gulati, P. R. 2010. "Change for Change's Sake." Harvard Business Review, June

- Piderit, S. K. (2000). "Rethinking Resistance and Recognizing Ambivalence: A Multidimensional View of Attitudes Toward an Organizational Change," Academy of Management Review, October 1, vol. 25 no. 4 783-794, CrossRef, CrossRef

- Porter, M.E. (2008). "The Five Competitive Forces That Shape Strategy", Harvard Business Review, January 2008, pp. 79-93

- Recker, J. (2005). "Process Modeling in the 21st Century". BP Trends, May 2005

- Simon, H. A. (1956). "Rational Choice and the Structure of the Environment". Psychological Review 63 (2): 129-138, CrossRef

- Stinchcombe, A. L. (1990). Information and Organizations. University of California Press: Berkeley and Los Angeles, California

- Tsoukas, T. (2002). "On Organizational Becoming: Rethinking Organizational Change," Organization Science, Volume 13, Issue 5, CrossRef

- Weick, K. (1977). "Enactment Processes in Organizations," In B. M. Staw \& G. Salancik (Eds.), New Directions in Organizational Behavior (pp. 267-300). Chicago: St. Clair 